\title{
Nuevas claves para el estudio de la historia militar argentina. Por una mirada más allá de la «Ley Riccheri»
}

Aldo Avellaneda* Hugo Quinterno**

\begin{abstract}
Resumen
La «Ley Riccheri», sancionada en diciembre de 1901, ha cumplido la función tácita de un umbral en la historiografía militar en Argentina. Hacia atrás, el "viejo ejército" de las levas y las fronteras. Hacia adelante, el ejército de la conscripción, con pretensión industrialista y moderno. Esto ha llegado incluso a pautar líneas de investigación diferenciadas. Este artículo aspira a poner en discusión este lugar otorgado a los primeros años del siglo y a la legislación citada. Lo hace ubicando la ley en un contexto de larga duración y reponiendo los juicios y percepciones de los propios actores en los primeros años de su implementación. Se otorga especial atención además al programa de organización militar de 1905, y a algunos de sus efectos percibidos para los días del Centenario.
\end{abstract}

Palabras clave: Ley Riccheri - Ejército - Modernización

\section{Summary}

The "Riccheri Law", which was sanctioned in December 1901, has fulfilled the tacit function of a threshold in the military historiography in Argentina. Backwards, the "old army" of levies and borders. Moving forward, the conscription army, with an industrialist and modern pretense. This has even led to different lines of research. This article aims to put into discussion this place granted to the first years of the century and to the cited legislation. It does so by placing the law in a long-term context and restoring the judgments and perceptions of the actors themselves in the first years of law implementation. Special attention is also given to the 1905 military organization program and some of its perceived effects for the Centennial days.

* Universidad Nacional del Nordeste.CONICET. E mail: aldoavellaneda.ces@gmail.com

** Universidad de Buenos Aires. 
Keywords: Riccheri Law - Army - Modernization

\section{Introducción}

Una de las preocupaciones más significativas de la tradición historiográfica fue la de datar a los procesos políticos y a las instituciones de forma taxativa. Así, cada gran momento de la historia nacional tiene una fecha precisa y un acto administrativo que oficia como partida de nacimiento. Por poner unos pocos ejemplos: la organización nacional se marcó en 1853 con el dictado de la Constitución y la Argentina moderna en 1880 con la sanción de dos leyes (capitalización de Buenos Aires y prohibición de levantar ejércitos provinciales). En idéntico sentido en 1900-01 surgió el "nuevo Ejército", en coincidencia además con el cambio de centuria, alumbrado por la creación de la Escuela Superior de Guerra primero y por el dictado de la ley 4.031 de servicio militar obligatorio, un año más tarde. En este último caso - como en otros de nuestro pasado - la norma jurídica se ha dotado hasta de un nombre propio que la identifica: "Ley Riccheri".

Junto a lo anterior cabe preguntarse por el lugar que quizá sigan ocupando los textos del derecho positivo en las apreciaciones y juicios de los balances historiográficos sobre procesos institucionales y/o colectivos de la vida militar. Por caso, y respecto a la "Ley Ricchieri", su centralidad puede ser entendible en la literatura institucional que pone en paralelo la elaboración de un relato historiográfico y la legitimación de la propia institución, definiendo su prehistoria, su presente y su futuro (aunque no debieran desestimarse los procesos de revisión también en este tipo de literatura). Otro puede ser el caso, sin embargo, del campo académico-historiográfico (siempre sobre este tema en particular). Los que podrían denominarse "trabajos clásicos" - como los estudios de Alain Rouquié, Darío Cantón, Miguel Ángel Scenna e incluso el ejercicio de contextualización de Virgilio Beltrán y Jorge Ochoa de Eguileor en su obra sobre el pensamiento de los cuadros militares de mediados del siglo XX - han asumido a la "Ley Ricchieri" como un principio de discontinuidad en la vida militar en Argentina. Esta misma operación puede observarse de modo tácito en algunos estudios recientes y de modo explícito en trabajos como el de Nicolás Silliti que adjudican una efectividad a la "Ley Riccheri" (en su caso respecto a representaciones de nacionalización y control 
social) que los propios cuadros militares de la época parecen no haber percibido o experimentado, al punto de haber impulsado su modificación, cuatro años después de su sanción.

Las lecturas en estos y otros trabajos de un proceso de profesionalización y modernización - o del ejército mimetizándose al sueño liberal-reformista de control social y unificación cultural - ofrecen una visión de la "Ley Riccheri” y del mundo militar en la primera década del siglo XX que consideramos merece ser repensada, en ningún caso para desvincular al ejército de estos temas sino más bien y precisamente para delimitar de un modo más realista la ubicación de esta legislación así como las controversias que suscitó, en relación a aquellos.

En este sentido, nuestra propuesta se basa en tres pilares: el seguimiento de la ley en los años siguientes a su sanción, la reposición de la voz de los actores históricos contemporáneos y el trazado de líneas vinculantes con los acontecimientos políticos y sociales del período en cuestión, ya que ninguna legislación opera al margen de estos acontecimientos. El objetivo del artículo es en consecuencia contribuir a precisar la "Ley Riccheri" como un elemento de un proceso más amplio, que fue importante en algún sentido, pero solamente tuvo un peso relativo en otros. Por caso, y como intentaremos poner de manifiesto, aun varios años después, y hasta el Centenario por lo menos, existieron más continuidades que rupturas en la estructura del ejército como organización armada, así como en la formación de combatientes.

El escrito está organizado en cinco apartados, independientes en sus temáticas pero relacionados en cuanto a sus derivaciones. La primera sección revisa someramente las discusiones sobre los mecanismos de reclutamiento y el problema de la instrucción militar desde las últimas décadas del siglo XIX, repasa algunas de las soluciones adoptadas y muestra lo escasamente novedoso del sistema de conscripción definido en 1901. Asimismo, a través de las visiones de los contemporáneos, exhuma las reflexiones y críticas formuladas en torno a su funcionamiento y sus falencias.

Si en este apartado las voces que se expresan son fundamentalmente de militares y ensayistas castrenses, en el siguiente recuperamos la forma en que estas repercuten sobre la política, en un momento de crisis dentro de la coalición gobernante. Esta circulación de ideas llevó a un escenario tumultuoso, cuya culminación fue la revolución radical de febrero de 1905. El levantamiento fracasó pero, como podrá 
apreciarse en la tercera sección, tuvo como uno de sus efectos en el invierno siguiente una revisión profunda de la normativa de 1901 que en muchos casos significó volver sobre sus pasos, ya que para muchos era la causante principal del malestar.

El cuarto apartado se ocupa de seguir el desempeño de desarrollos institucionales y de algunas variables escogidas una vez operativa la nueva legislación (regionalización, agarre territorial del ejército, reclutamiento de suboficiales), y destaca la lentitud con la que se efectivizaron los cambios. Justamente la quinta sección releva la situación hacia el Centenario y expone los límites del aparato estatal para llevar adelante el sueño reformista. En este segmento incorporamos también las apreciaciones de observadores externos que dieron sus opiniones sobre el ejército en ese momento. Finalmente, se presentan unas conclusiones que señalan los resultados provisionales de esta investigación y nuevos interrogantes para futuras pesquisas.

\section{La «Ley Riccheri» en un plano de larga duración. Variantes al interior del mundo militar}

Tal vez una de las razones por las que la "Ley Ricchieri” ha ocupado un lugar destacado en la historiografía militar, es que no ha sido ubicada en los debates y concepciones sobre organización militar, particularmente sobre instrucción militar y dotación de recursos, en el largo plazo. El año de 1880 ha sido utilizado de un modo canónico en la historiografía argentina, precisándose en esa fecha un "cambio de época". En la periodización de nuestra historia política en los textos escolares, esto resulta evidente. Con razones valederas, la historiografía ha relativizado esa segmentación, aunque para el caso que nos ocupa, 1880 puede ser mantenido como un terreno de referencia. Y ello por dos razones. En primer lugar, porque el proceso contencioso de nacionalización de los recursos militares - que ya venía desarrollándose desde tiempo atrás - tiene particular empuje en ésta y en la década siguiente. En ese sentido, puede verse a la legislación del Servicio Militar Obligatorio (SMO) como la coronación de dicho proceso, aunque esto no haya significado en ningún caso su cumplimiento 
efectivo aún. ${ }^{1}$ Por otra parte, porque la victoria contra el principal contendiente potencial del estado nacional (la lucha armada con las Guardias Nacionales de Buenos Aires), otorgó gradualmente a los cuadros militares del ejército la novedosa percepción de un lugar indisputado en cuanto a potencia militar en el territorio nacional (aunque los escarceos efectivos en territorio aún subsistieran varios años). Algunos de los aspectos más sobresalientes de este nuevo trasfondo están vinculados con las maniobras, a la vez especulativas y prácticas, con las que intentaron dar cuenta de los dos problemas considerados como fundamentales: la dotación de personal y la instrucción militar de los Guardias Nacionales. ${ }^{2}$

Puede verse a lo largo de esas dos décadas que separan la victoria del ejército de Línea sobre las Guardias Nacionales (en adelante, GN) de la provincia de Buenos Aires y la sanción de la "Ley Riccheri", un movimientismo intelectual y administrativo singular en el mundo militar con respecto a estos temas que, aunque no produjesen cambios significativos en la estructura del ejército (como tampoco la mencionada ley), sirven para visibilizar la hipótesis de este artículo, destinada a relativizarla como aspecto central y fundante del "ejército moderno".

Empezada la anteúltima década del siglo XIX, los modos de incorporación de personal al ejército se daban según las cuatro formas pautadas por la legislación de 1865 y 1872: los enganchados, los contratados, el voluntariado y los contingentes. En la práctica, de todas estas formas la última era realmente crucial, al resultar el único mecanismo que permitía el ingreso de jóvenes al ejército, de un modo a duras penas regular. ${ }^{3}$ En el envío de contingentes, quedaban expuestos aspectos como las bajísimas expectativas de los jóvenes para encarar una carrera de armas (pues el número de voluntarios era casi nulo), o las complejas vicisitudes políticas entre las provincias y el estado nacional (algo que puede verse en las continuas quejas de los ministros de guerra, luego de cada llamado).

1 Quinterno, 2014.

2 Avellaneda, 2017a, 2017b.

3 Pueden consultarse las Memorias del Ministerio de Guerra, a lo largo de la década de 1870 para su comprobación. Ya en 1877, y debido al desprestigio de las levas forzadas, se había discutido en el Congreso un mecanismo de licenciamiento de los contingentes retenidos indebidamente, que no obtuvo sanción. 
En 1888 se dio el primer intento de reclutamiento sin atender a las opciones del voluntariado y los contratos. ${ }^{4}$ Ese año, producto de la presión que suponía el ejército nómade dispuesto a una empresa de colonización interna al sur y al norte del territorio y de las evidencias acumuladas sobre la ineficacia de las otras opciones, se suprimieron las oficinas de enganche y se intentó obtener recursos exclusivamente por la vía de los sorteos sobre las GN. Para el ministro de Guerra, “hoy, $[\ldots]$ el servicio militar obligatorio [...] viene sin duda alguna a traer a las filas del ejército otra clase de soldados, con más ilustración y dotados del espíritu que corresponde; se diseña con su verdadero carácter esta Institución...". ${ }^{5} \mathrm{La}$ fórmula de un "servicio militar obligatorio" resulta, pues, presente de modo explícito cerca de una década y media previa a la "Ley Riccheri", aunque en sus enunciaciones de la década de 1880 no incluía el registro de la instrucción militar. ${ }^{6}$ El resultado de ese intento de 1888 fue fuertemente criticado y se percibió además con desazón por quienes lo impulsaron, ajustando sus expectativas a un agrio realismo. ${ }^{7}$

La inestabilidad política de principios de la última década del siglo XIX ha sido objeto de muchas revisiones. Sin embargo, un punto particular para este trabajo es el lugar ocupado por la Guardia Nacional en las revoluciones de 1890 y 1893. Las GN participaron en los conflictos del lado de los amotinados, pero también, y a diferencia de lo sucedido en 1880, en el bando oficialista. Los informes militares señalaban el grado de movilización de las Guardias Nacionales de Buenos Aires, Córdoba, Santa Fe, entre otras provincias. ${ }^{8}$ En el estudio sobre la revolución de 1893 en Santa Fe, las Guardias Nacionales aparecen más bien formando parte de los grupos armados del estado nacional que reprimieron a los colonos suizos que se habían unido a los militantes radicales ${ }^{9}$. En parte debido a esto - y también al mejoramiento relativo del

\footnotetext{
4 Esto resultó algo disputado al interior del ejército pues existían espacios (como la Revista Militar) desde los que defendía en ese momento la opción del libre ingreso, basados en una suerte de innatismo caracterológico. Algunas piezas que pueden observarse son, del Cnel. Figueroa: "Consideraciones sobre la obediencia" (1886, pp. 3-13) y "Cualidades y virtudes militares" (1886, pp. 171-199); del Cnel. Mendoza: "Necesidad de estudio y asociación", 1885, pp. 43-49, "Reformas" (1886, pp. 241-252) y “De la disciplina" (1886, pp. 253-282).

5 Memoria del Ministerio de Guerra y Marina, 1888: 235, en adelante MMGM, 1888: 235. Puede consultarse además $M M G M, 1887$ : III-IV,

6 MMGM, 1888: 22-25

7 MMGM, 1889, Informe del Estado Mayor, pp. 3-4; MMGM, 1894, Tomo 1: XI.

8 Un informe pormenorizado de la movilización de la Guardia Nacional por provincia en el "Anexo" a la $M M G M, 1894$, pp. 179-267.

9 Gallo, 2007: 79
} 
sistema de enrolamiento, que permitía una mirada más sutil sobre el número de jóvenes que estaban en condiciones de alistarse a las Guardias Nacionales - lo percibido como problemas fundamentales cambió de dirección. ${ }^{10}$ El problema para los cuadros militares en esos años de la última década ya no era solamente la dotación de personal sino también la instrucción militar. ${ }^{11}$ Tanto es así que el proyecto de 1895, que dio lugar a la llamada "Primera Conscripción", concebido en principio como un programa de instrucción militar y no de dotación de personal, resultó desvalorizado por el propio ministro de Guerra al poco tiempo de ser aprobado:

La ley de organización del ejército y de la G.N dictada por V.H. en las sesiones del año pasado, vino a solucionar en parte los inconvenientes apuntados, disponiendo que los ciudadanos de 20 años fueran incorporados al ejército permanente por el término de un año, y recibieran instrucción militar por lo menos durante sesenta días... Pero subsiste el problema de la remonta del ejército veterano, cuya existencia en la actualidad y probablemente por bastante tiempo, es una necesidad imprescindible entre nosotros ${ }^{12}$

Pero el que tal vez sea el factor que más ha pasado desapercibido a la literatura es el hecho de que la entrada regular y relativamente masiva de jóvenes a los cuarteles se dio en el marco de una coyuntura crítica particular y bajo una normativa menor, un par de años antes al debate de la "Ley Riccheri". El 23 de mayo 1898 bajo el clima de excitación ante un posible conflicto armado con Chile se aprobó la ley 3.686 (una modificación de la ley de 1895), "estableciendo el servicio obligatorio para la instrucción militar de la Guardia Nacional' (son los términos de Ercilio Domínguez), y por la cual quienes debían realizar sus campamentos ese año pasarían luego a revistar en los cuarteles, siendo reemplazados a los seis meses. ${ }^{13}$ Esta legislación, que fue operativizada aún con

10 En cuanto a los cambios en las redes para el enrolamiento en esa última década, ver Avellaneda, 2019.

11 Una mirada comparada puede hacer surgir claramente las diferencias. Mientras en la década de 1880, los contados proyectos de instrucción militar tenían como blanco al personal permanente, en la década siguiente - y más allá de las diferencias en cuanto a concepciones de organización armada - el blanco lo constituyen los Guardias Nacionales (el proyecto del Depósito de Reclutas de 1892, la reactivación de los Ejercicios Doctrinales en 1893, la propuesta de las Academias Militares en 1895 y las movilizaciones a campamentos entre 1896 y 1898).

12 MMGM, 1896: 7-8

13 El "Plan de Movilización" de acuerdo a la ley de 1895 se había aprobado el 28 de febrero de 1898 (Ver Domínguez, Ercilio, 1898: 130 y 150, en adelante CLyDM, 1898: 130 y 150). Pueden consultarse 
todos los problemas imaginables de logística y agarre territorial, existía en plenitud en los días del debate de la "Ley Riccheri” y las páginas de la Revista Militar mostraban con claridad el transporte por tren de los "conscriptos" que eran enviados a las unidades desplegadas en Buenos Aires. ${ }^{14}$

De este modo, no solamente la "Ley Riccheri" no resultó "un rayo en un día sereno" - pues los problemas y las preocupaciones que le dieron cabida en el Congreso en 1901 ya existían por lo menos desde hacía dos décadas en el mundo militar - sino que ni siquiera resultaron una novedad sus efectos concretos, es decir el envío compulsivo de jóvenes a los cuarteles (más allá de lo que llegó a legislar respecto a la organización militar, particularmente en cuanto al tiempo de permanencia en los cuarteles y a las reservas). Precisar estas cuestiones resulta de fundamental importancia, no para desvalorizar o relativizar el peso de la legislación, sino para otorgarle una dimensión más equilibrada, en tanto dispuesta en una mirada de larga duración.

Ahora bien, si la "Ley Riccheri" puede tomar una coloración más realista al ser colocada sobre una horizontal comparativa, otro tanto ocurre al tener en cuenta las reacciones en el mundo militar a los efectos de su implementación. Uno de los aspectos que aparecen sin dudas como sorprendente a la luz de la literatura, es que para sus contemporáneos, lejos estuvo de ser considerada como un avance en la dirección de un ejército profesional y moderno. A mediados de 1900, un oficial se quejaba en la Revista Militar de las condiciones en que los "conscriptos" (los que eran enviados a los cuarteles desde 1898) pasaban su tiempo en las cuadras.

Hasta abora en nuestros batallones de linea no se prepara en realidad al soldado para el combate, sino para ser aplaudido en los desfiles y revistas en las calles de la metrópoli y demás capitales de la República, dándosele mayor importancia, no

además los números del Semanario Militar del 8 de marzo, 1 y 16 de abril y 8 de mayo para ver detalles respecto a hombres y unidades. En Tandil se reunieron más de 6.500 individuos entre tropa veterana y conscriptos, y en total la movilización de ese año parece haber afectado a cerca de 30.000 personas. No llegaron a coronar con las maniobras de grandes unidades. La sanción de la ley de mayo cambió todo de eje, y dio consistencia normativa-territorial a la preocupación de vieja data por los recursos, relativizando aquella hegemónica en ese momento (la instrucción militar). De las concentraciones a cielo abierto se pasó a los cuarteles en cuestión de meses. Para noviembre de 1898, la realidad era otra. El contingente de conscriptos que había sido movilizado a campamentos en abril, recién fue licenciado a principios de noviembre, al tiempo que nuevos contingentes tomaban su relevo (ver CLyDM, pp. 183, 207, 211-213). Todo debido en buena medida a la coyuntura crítica de una posible confrontación con Chile.

14 Ver "Esquema de movilización de la Pcia. De Buenos Aires", en Revista Militar, 1900, p. 645. 
sabemos por qué causa, a la instrucción que enseña a marchar con marcialidady llevar correctamente el arma sobre el hombre, que a aquella que saca del soldado un elemento útil en la acción ${ }^{15}$

En el número siguiente, otro oficial profundizaría el diagnóstico, al preguntarse "¿Qué se hace con los conscriptos que pasan por las filas vegetando en ciertos cuerpos durante meses?", y responderse a sí mismo diciendo que "se hace un fatigoso servicio en la Penitenciaría, en el Arsenal, en Polvorines, Casa de Gobierno, etc.; no dudo que se trabaja, pero esta rama importantísima de la instrucción militar pasa a ser de las últimas en vez de ocupar el primer rango que le corresponden". ${ }^{16}$

Pues bien, luego de legislada y en los primeros años de su implementación, la "Ley Riccheri” fue objeto de críticas más severas en la misma dirección. ${ }^{17}$ Quizá el mayor de los ataques que debió soportar el programa del servicio militar en sus primeros años provino del Teniente Coronel Augusto Maligné, quien para la asunción del presidente Quintana a fines de 1904 redactó un "inventario de las existencias de una bancarrota" a fin de describir el modo en que el ejército había sido "desarmado, desarticulado, deshecho, en los cuatro años transcurridos desde el 20 de septiembre de 1900", fecha de la asunción efectiva de Riccheri como ministro de Guerra. El panorama retratado por Maligné resultaba desalentador. Los altos niveles de excepción para las clases medias y altas y de deserción de las capas populares, la imposibilidad de la instrucción militar de aquellos que a pesar de todo ingresaban a los cuarteles, la inexistencia de clases para formar a los conscriptos o las fallas de las divisiones regionales en relación con el mecanismo de reclutamiento, daban como resultado un ejército sin recursos y una población sin instrucción militar. ${ }^{18}$

15 Revista Militar, julio de 1900, p. 251.

16 Revista Militar, agosto de 1900, p. 371.

17 Ya en noviembre de 1902 (a menos de un año de la sanción de la ley), un artículo de la publicación castrense afirmaba que "se ha comprobado, según se dice, que la Ley Militar necesita algunas modificaciones", pero solicitaba prudencia en los juicios y paciencia para formularlos, dando más tiempo para interpretar los resultados de la nueva organización (Revista Militar, noviembre de 1902, pp. 740-742, véase también Revista Militar, enero de 1904, p. 6). El ambiente entre los grupos de oficiales era retratado además en un tono preocupante a finales de 1903 (Revista Militar, diciembre de 1903, pp. 591-593). Debe señalarse además que al año siguiente de su sanción, el Gral. Campos, con el apoyo de otros jefes militares, presentó un proyecto de anulación de la vía militar adoptada (Diario de Sesiones de la Cámara de Diputados, 1902, p. 192, en adelante DSCD, 1902: 192).

18 Maligné, 1904: 5 
En 1905, los escritos en la Revista Militar enjuiciaban en un tono áspero el efecto de la ley, ya que privilegiaba el servicio a la instrucción militar:

Para que la ley 4031 se cumpla más por voluntad que por fuerza, las conscripciones deben bacerse con el sólo y único objeto de la instrucción militar obligatoria y no del servicio, que es tan desigual, tan pesado y tan poco provechoso, como nos lo ha demostrado la experiencia [...] El servicio militar se distingue de la instrucción, en que a que no deja tiempo cumpliéndolo rutinariamente al cuidado de las fronteras, en guardas pretorianas, en paradas y desfiles ${ }^{19}$

La supuesta utilización de los conscriptos en tareas ajenas a las que ya se criticaban porque demandaban una falta de atención a la instrucción militar, parece haber sido de tal magnitud que en febrero de 1906 se emitió una disposición interna prohibiendo a los oficiales tomar como oficinistas o asistentes a los conscriptos. ${ }^{20}$

Lo singular en la "Ley Riccheri” fue que hizo entrar en la consideración de la agenda militar una "diferencia cultural" que provenía del mundo social y civil. Cómo tal vez no había ocurrido antes, los propios cuadros militares fundamentaron su sanción y la defendieron de las críticas luego de su implementación, apelando a argumentos ajenos y externos al campo militar (la importancia para los jóvenes, la cuestión del cosmopolitismo y el problema de los inmigrantes, etc.). Pero por esa misma razón, llegó a resultar a los juicios de una parte importante del cuerpo de oficiales como algo reñido con un espíritu profesional.

Lo que aparecía devaluado en las líneas argumentales de apoyo al proyecto de Roca y Riccheri era cualquier tipo de concepción de la instrucción militar como meramente técnica. A diferencia de la ley de 1895, promotora de un programa de instrucción militar que incluso llegó a incorporar la movilización de grandes unidades, la "Ley Riccheri” recibió críticas en los primeros años de su implementación precisamente por no atender debidamente la instrucción militar en los conscriptos, y hacer pesar el servicio en prestaciones internas (guardias, ronda, limpieza, patrullas) así como en asistencia de seguridad a otras instituciones. Y todo esto para los jóvenes que llegaban

19 Revista Militar, marzo de 1905, p. 188. Esta cita y el párrafo referido a Augusto Maligné, recuperados de Avellaneda, 2017a: 78-79. Para un detallado repaso de las vicisitudes del desempeño del Ministerio de Riccheri, así como de la ley 4.031, ver Quinterno, 2014: 166-174.

20 Colección de Leyes y Decretos Militares, en adelante, CLyDM, 1906, Tomo 6: 59. 
a ser efectivamente incorporados a los cuarteles ya que, como se ha visto, los problemas de logística y agarre territorial para su implementación fueron por largos años una compañía insidiosa.

Sobre este trasfondo (sumado a otros problemas que serán expuestos más abajo) debe comprenderse la reforma militar encarada en 1905. Fue presentada como la que "viene a corregir los errores" de la "Ley Riccheri”. En sus exposiciones, el general Campos y el coronel Domínguez desplegaron argumentos relativos al muy pobre desempeño de la legislación para llevar a los jóvenes a los cuarteles, así como el creciente malestar y descontento de los oficiales por la situación de inercia en los ascensos y los magros salarios. ${ }^{21}$ Cuatro años después de su sanción, era imperioso presentar una nueva legislación que aspirase a proponer no pocos cambios respecto de la normativa de 1901. Pero antes de dar cuenta de esta nueva legislación - y el trasfondo de debates y reflexiones en las que estuvo envuelta así como la dirección de los nuevos avances programados - es necesario una mirada al exterior del mundo militar, específicamente al campo político que rodeó esos breves años de existencia de la "Ley Riccheri".

\section{La situación interna en el mundo militar y su relación con el campo político}

Dentro de las constantes del discurso historiográfico en torno a la ley militar de 1901 se ha hecho hincapié en dos elementos centrales: la valoración de la hipótesis del conflicto con Chile y la cuestión de convertir al servicio militar en el "crisol de la argentinidad" donde se fundieran las almas de los jóvenes reclutas, en su mayoría hijos de la gran oleada inmigratoria procedente de Europa. Basta leer las opiniones de los contemporáneos o enfocarse en el desarrollo de los acontecimientos que siguieron a la implementación de la ley, para ver que estos aspectos lejos parecen haber estado de tener un impacto significativo.

En cambio, poco se revisó la necesidad de este ordenamiento legal para las fuerzas armadas (así como sus dificultades operativas) a la luz de la evolución de los conflictos

21 DSCD, 1905: I, 170-171 у 175. 
que estallaron al interior de la coalición gobernante, cuyo lento pero irreversible desgajamiento se extendió hasta 1916. Tal vez el punto de quiebre de esa tensión pueda datarse en el invierno de 1901, con el fracaso de la iniciativa de consolidar la deuda externa nacional a través de un arreglo de largo plazo con los acreedores. El desaire del presidente Roca al proyecto impulsado por el senador Carlos Pellegrini produjo finalmente una fisura insalvable entre estas dos figuras y liquidó lo que desde años antes era algo así como un matrimonio por conveniencia. Producto de la ruptura el viejo Partido Autonomista Nacional (PAN) se desmembró, surgieron nuevas facciones y el orden político se volvió bastante inestable. ${ }^{22}$

En buena medida, las desavenencias iniciadas en julio de 1901 - que llevaron incluso a la necesidad de declarar el estado de sitio en la Capital Federal - se tradujeron en las distintas posiciones expuestas durante los debates de la "Ley Riccheri" a partir de septiembre. Más allá de la discusión sobre supuestos modelos de organización militar, los diputados que enfrentaron al ministro (y a través de él al propio jefe de estado) eran voceros de los grupos díscolos nacidos al calor de la fractura en la coalición. Enrique Godoy, Ramón Falcón y otros legisladores, muchos de ellos militares, no estaban en contra de la conscripción y habían hecho manifestaciones favorables a esta forma de reclutamiento en las distintas oportunidades en que se debatieron proyectos sobre organización del ejército, como en 1895 y 1898. Pero fue categórico el apoyo que expresaron en 1900 en ocasión de aprobarse la ley de reclutamiento de la marina de guerra, cuya forma no difería sustancialmente del mecanismo adoptado en 1901. En la discusión del asunto, Godoy sostuvo lo siguiente: "Yo, señor presidente, he de votar por el servicio obligatorio, por la conscripción en mi país, porque asi creo que lo exigen las circunstancias; porque nuestros vecinos están militarizándose y creo que corresponde á nuestro país tomar idénticas precauciones". ${ }^{23}$

La pérdida de influencia y poder de Julio Roca, la consecuente reorganización de sus opositores, los resquemores de buena parte de los jefes del ejército y el accionar de

22 Sommariva, 1931, Melo, 1970, Peck, 1980, Barba, 2000, Botana \& Gallo, 2007.

23 Quinterno, 2014: 155-156. Ver DSCD, 1900: 930. Finalmente Godoy votó en contra de la ley, pero solo porque planteaba distintos tiempos de permanencia en filas, mientras él pretendía una prestación homogénea en cantidad. El proyecto fijaba dos años para los conscriptos de la armada mientras que, según la ley vigente de 1898, los del ejército prestaban hasta un año de servicio. Por ello, en 1901 se hizo bianual el máximo de tiempo de servicios en las fuerzas de tierra. 
algunos gobernadores con pretensiones de saltar al primer plano de la política nacional (como el caso del bonaerense Marcelino Ugarte) fueron un obstáculo permanente para los planes del ministro de Guerra, cuyo único sostén era su amistad con el presidente. En este sentido, los diputados y senadores críticos de la administración retacearon los recursos necesarios para hacer efectivas algunas de las propuestas reformistas de Riccheri al sancionar los presupuestos de 1903 y 1904 y dejaron sentir su disgusto cuando, en un intento desesperado para lograr consensos, el grupo gobernante llevó adelante la denominada "asamblea de notables" destinada a elegir de entre su seno a la fórmula presidencial que tomaría el timón del país en octubre de 1904.

La debilidad de Roca en el último tramo de su mandato terminó siendo sorprendente. Un dato no menor fue el rechazo del Senado al pliego de un candidato propuesto para integrar la Corte Suprema de Justicia, un hecho inédito hasta entonces, que resultó tan llamativo como para que por un conocido publicista lo citase como un atípico desplante del parlamento a la voluntad presidencial. ${ }^{24}$ Otro acontecimiento interesante se produjo en junio de 1904, cuando Roca no consiguió sostener en el gobierno de San Luis a los hermanos Mendoza, derrocados por una sedición local. Apenas si el regimiento 13 de infantería y el interventor enviado a la provincia consiguieron salvaguardar la vida de estos políticos, tras verse obligados a convalidar el triunfo de los revolucionarios, una heterogénea agrupación de disidentes del PAN, radicales y autonomistas. $^{25}$

Junto con este ruido en la cúpula, las deficiencias en la gestión del presidente y su secretario de Guerra también alimentaron la disconformidad de los oficiales jóvenes. Mayores, capitanes, tenientes y subtenientes se decepcionaron prontamente con Riccheri (si es que alguna vez habían tenido esperanzas en él) al ver que, a pesar de las repetidas promesas hechas por el ministerio, temas tan sensibles como la falta de cierre del escalafón o la atención del problema de los magros salarios se postergaban una y otra vez en el marco de la cada vez más errática política del departamento castrense, que con sus vacilaciones y reformas a medio hacer motivaba el enfado de los oficiales de baja graduación, el desdén de los cuadros superiores y las burlas de la prensa, como

24 Matienzo, 1910: 137.

25 Gez, 1905. 
bien reflejó la portada de la edición de abril de 1902 de Caras y Caretas, al calificar a la conducción de Riccheri como un "ministerio sin pies ni cabeza". ${ }^{26}$

Este mal clima facilitó la recepción de la prédica de Hipólito Yrigoyen en la oficialidad menor y la creación de un clima insurreccional dentro de los regimientos. Según evocó quien entonces era un joven subteniente, a mediados de 1904 quizá dos tercios de esos cuadros simpatizaban con el radicalismo o, por lo menos, estaban dispuestos a levantarse en armas antes del recambio presidencial. ${ }^{27}$

En esa apelación a la sublevación, tanto el líder radical como algunos de sus lugartenientes criticaban a la conducción de las fuerzas de tierra y a las políticas ministeriales pero exaltaban al ejército y a sus viejas glorias, en un intento de llamar a la redención de la institución por medio de la vía revolucionaria y a través de sus propios oficiales jóvenes, un argumento típico de la UCR desde sus días fundacionales. Incluso dentro de la dirigencia no faltaba quien aprovechaba la ocasión para atacar la ley 4.031, como el presidente de la junta ejecutiva partidaria, Pedro Molina, quien luego del estallido de la revolución del 4 de febrero de 1905 sostuvo que, entre otras cosas, el alzamiento se produjo "contra la ley de reclutamiento militar que suprime de hecho por el tiempo de la conscripción la libertad de las personas, - y a favor del sistema de reclutamiento por contrato". ${ }^{28}$ El coqueteo de los radicales con la baja oficialidad del ejército fue un cambio de táctica con respecto a las revoluciones anteriores. Si en 1890 el compromiso para sublevarse había sido compartido desde sectores del alto mando hasta cadetes de la escuela militar, la fractura de los cívicos por la defección del mitrismo y el restablecimiento del orden interior una vez que Pellegrini se convirtió en presidente, llevaron a que en 1893 los jefes de la UCR desplazaran el soporte armado de la revuelta hacia las Guardias Nacionales, en especial aquellos regimientos de la provincia de Buenos Aires donde la influencia de Alem o Yrigoyen hundía sus raíces en los tiempos del autonomismo. ${ }^{29}$ Con la ley militar de 1901, que al nacionalizar los servicios militares literalmente desmanteló las estructuras de la antigua formación miliciana y le quitó el acceso a las armas, fue necesario reclutar adeptos entre los cuadros de graduación inferior ya que

26 Caras y Caretas, año V, n 184, abril 12 de 1902, tapa.

27 Reynolds, 1969: 11.

28 Fanelli, 1905: 44.

29 Etchepareborda, 1968. 
eran los únicos sujetos con capacidad para movilizar a los batallones contra el gobierno.

No es sencillo precisar cuándo se pusieron en marcha las acciones preparatorias del alzamiento militar de 1905, pero ya en el invierno de 1903 un informante anónimo le advirtió a Roca que el "ejército está por sublevarse" y le dio detalles sobre los principales oficiales comprometidos tanto en el arsenal principal como en el propio ministerio, a pasos del despacho presidencial. ${ }^{30}$

El periodismo también se hizo eco de la inquietud. Durante septiembre de 1904, en la revista Caras y Caretas se mencionó la existencia de una conspiración y se exponía la ansiedad de los jefes policiales y militares, quienes vivían en situación de alerta. ${ }^{31}$ Pocos días después, el semanario prestó bastante atención a las violentas manifestaciones de los estudiantes de derecho de la Universidad de Buenos Aires que, con la excusa de una cuestión administrativa, destrozaron varias oficinas de esa facultad e hicieron disparos intimidatorios con armas de fuego. Sobre tales episodios, la revista opinó que "este bochinche no es más que el aperitivo de los que se anuncian". ${ }^{32}$

El clima de crispación se intensificó en la semana siguiente cuando la policía allanó varios domicilios, secuestró al menos ochenta fusiles remington y se mantuvo en alerta permanente, a punto tal que los jefes de la policía de la Capital y del ejército dormían en sus oficinas y los cuerpos militares del gobernador Ugarte patrullaban sin descanso las calles de La Plata. ${ }^{33}$

Roca y Riccheri apenas pudieron evitar el estallido revolucionario trasladando a oficiales sospechosos desde las guarniciones del área metropolitana hacia las provincias del interior, desplazamientos que - de forma paradojal - ayudaron a los radicales a nacionalizar el complot al sumar nuevos batallones a la trama insurreccional, según relató más tarde un dirigente de la UCR. ${ }^{34}$

Cuando finalmente Julio Roca transfirió el mando a su sucesor, los rumores eran de tal entidad que el nuevo jefe de estado - en su discurso de posesión del cargo - habló

30 Anónimo al presidente Roca, junio 27 de 1903, citado en García Molina, 2001: 613.

31 "Alarmas", en Caras y Caretas, Año VII, n 311, septiembre 17 de 1904.

32 "Los desórdenes de la Facultad de Derecho, en Caras y Caretas, Año VII, n 312, septiembre 24 de 1904.

33 "Las alarmas" y "Las alarmas en La Plata", en Caras y Caretas, Año VII, n 313 octubre 1 de 1904. 34 Caballero, 1949: 38. 
de la necesidad de atender la cuestión de los ascensos y el cierre del escalafón. Quintana consideraba "indispensable una ley de reforma militar" pero reclamó al paciencia al ejército y lo instó a mantenerse "extraño a las agitaciones de la política". ${ }^{35}$ Meses después del estallido, en mayo de 1905, el presidente reconoció la gravedad de la situación al momento de su asunción y empezó su alocución ante la asamblea legislativa reseñando la asonada de febrero. Allí señaló: "Al recibirme del gobierno conocía ya la conspiración que se tramaba". ${ }^{36}$

Como dijimos más arriba, los cambios en la conformación de las fuerzas de tierra por el proceso de nacionalización y la modificación del sistema de reclutamiento, llevaron a Yrigoyen y sus laderos a trazar un plan revolucionario que, si bien tenía vinculaciones con el de 1890, poseía también diferencias importantes. Como en aquel año, el corazón del motín consistía en la toma del arsenal principal de Buenos Aires, mudado desde su ubicación frente a la Plaza Lavalle, en el centro de la capital, al actual barrio de Parque Patricios, donde también tenían sus guarniciones dos regimientos de infantería. Ese golpe inicial debía acompañarse con la neutralización de varias comisarías porteñas y después reforzarse con las armas, municiones y explosivos que los insurrectos pensaban obtener del parque. Por efectos de la centralización, una vez tomada la cabeza de la nación, el resto del país caería por su propio peso. ${ }^{37}$

Para asegurar el levantamiento en la Capital Federal, los radicales tendrían asimismo el apoyo del regimiento 8 de caballería y esperaban plegar a escuadrones de Campo de Mayo. También los respaldaría el 6 de infantería que desde Bahía Blanca iba a moverse por tren hacia Buenos Aires para engrosar sus fuerzas con civiles que se sumarían en algunas de las estaciones intermedias. Mientras capturaban la sede federal, los alzamientos de los destacamentos cercanos a las capitales provinciales les darían el control de Rosario, Santa Fe, Mendoza y Córdoba, las principales ciudades del interior. En todas ellas los revolucionarios depondrían a los gobernadores, pero en Córdoba, además tenían como objetivo arrestar el vicepresidente Figueroa Alcorta y a Roca, que veraneaba en su estancia de Ascochinga. ${ }^{38}$

35 Diario de Sesiones de la Cámara de Senadores, 1904, p. 776, en adelante DSCS.

36 Mabragaña, 1910: VI, 112.

37 Barcia, 1981.

38 Fraga, 1997: 183-184. 
Un punto importante para los conspiradores, que asimismo favoreció la postergación de la fecha del estallido para inicios de febrero, era la escasa dotación de los regimientos en esa época del año. Al no haberse incorporado todavía a los conscriptos de la clase 1884 los batallones estaban con cuadros mínimos (en “esqueleto”, como se expresaban las fuentes uniformadas), apenas conformados por los conscriptos del servicio de dos años que en general revistaban como suboficiales junto a contratados. Incluso en el Colegio Militar, Riccheri (que pasó a ese destino al cesar como ministro) había licenciado a los cadetes hasta marzo debido al receso estival a pesar de conocer la posibilidad de un pronunciamiento. Por otro lado, pidió su relevo de ese cargo el 3 de febrero de 1905, algo que da cierto asidero a las declaraciones posteriores de Ricardo Caballero, quien habló de una media palabra del exministro a favor del alzamiento. ${ }^{39}$ De todos modos, los planes estaban bastante más claros en los borradores de sus mentores que en la realidad, sin contar con que en el Departamento de Guerra sabían los pormenores de la trama, al punto tal que conocían el santo y seña a usarse en las acciones militares. En la Capital, la noche anterior al 4 de febrero el ministro y altos oficiales de su confianza se instalaron en el Arsenal y, de a uno, fueron capturando sin demasiado alboroto a quienes tenían la misión de copar ese objetivo. Si bien los civiles radicales lograron tomar algunas comisarías, el respaldo de los demás regimientos porteños al gobierno hizo nacer muerta la revuelta en Buenos Aires, lo que liquidaba de antemano la insurrección. Así, al enterarse del fracaso, el batallón que venía desde Bahía Blanca se desbandó en la estación Pirovano (partido de Bolívar), no sin que antes se produjese un amotinamiento de suboficiales contra los revolucionarios, que dejó un saldo luctuoso, con varios civiles muertos. ${ }^{40}$

En el interior, en cambio, los revolucionarios tuvieron cierto éxito inicial mas solo pudieron sostenerlo brevemente. En Rosario, se alzaron el regimiento 9 de infantería y el 3 de artillería pero las milicias provinciales retomaron rápidamente la situación con apoyo de fuerzas bonaerenses y tropas nacionales leales al presidente. En Córdoba gracias a la adhesión del regimiento 8 de infantería y el 10 de caballería, y aunque la captura del gobernador Olmos y del vicepresidente fue conseguida (no así la de Roca),

39 Fraga, 1997: 182, Caballero, 1949: 146-148.

40 Beamonde, 1985, Navarro, 1906. 
los revolucionarios abandonaron sus planes al saberse inferiores y aislados y enterarse de los acontecimientos porteños. En Mendoza, el triunfo del primer momento, no exento de algunas escaramuzas violentas, se derrumbó al no poder extenderse al resto de Cuyo y se disolvió ante la certeza de la llegada de efectivos nacionales gubernistas. Una vez normalizada la situación, consejos de guerra especiales formados en cada región militar donde se vivieron las sublevaciones juzgaron a los oficiales involucrados. La mayoría de los cabecillas (algunos escaparon del país) fueron condenados a penas de prisión y un grupo pequeño de ellos fue enviado al penal de Ushuaia, mientras resultó más amplio el número de oficiales que no sufrió cárcel pero sí la baja del ejército. ${ }^{41}$ Entre los defensores de los acusados no faltaron personajes ilustres, como Roque Sáenz Peña, quien defendió al coronel Toscano y al capitán Olmos. Asimismo, también se disolvieron los cuerpos que habían tomado partido por la revolución, aunque casi todos fueron remontados tiempo después, una vez purgados de los oficiales levantiscos.

Algo destacado de esos juicios es que permiten apreciar uno de los aspectos de las quejas de la baja oficialidad que motivó el acompañamiento de la rebelión, a saber, la promesa incumplida del cierre del escalafón. Basta observar el elenco de algunos condenados en Buenos Aires y Córdoba, sus edades y rangos, para comprender la angustia de buena parte de esos cuadros inferiores que estaban notablemente retrasados en sus carreras profesionales. ${ }^{42}$ Tanto esto, como el duro balance sobre la gestión de Roca y Riccheri para con el ejército, la debilidad de la estructura militar exhibida durante los primeros momentos del levantamiento, las dificultades para convocar a las reservas, el fracaso para reclutar suboficiales con la ley de 1901 y el malestar generalizado dentro de las fuerzas, llevaron al gobierno a encarar sin más demora una reforma integral de la normativa militar.

\section{Las principales diferencias introducidas por la ley 4707 de 1905}

41 Guzmán, 1986.

42 Quinterno: 2014: 280. 
El 21 de mayo de 1905, el presidente Quintana y el ministro de Guerra Enrique Godoy enviaron al Parlamento un paquete normativo de seis partes, destinados a dar una estructura orgánica al ejército. Las secciones de esa entidad eran el reclutamiento, los cuadros y ascensos, los retiros, las pensiones, la reformulación de la intendencia militar y la modificación de los códigos de justicia. ${ }^{43} \mathrm{El}$ ambicioso proyecto fue en gran medida concebido por Augusto Maligné, quien como hemos visto era uno de los detractores más implacables de Riccheri. Incluso uno de los hijos del oficial participó activamente en los sucesos revolucionarios, pero los contactos de su padre lograron evitarle una condena en la instancia de su juzgamiento.

Como puede verse en los distintos títulos comprendidos en la iniciativa, las autoridades buscaban un ordenamiento globalizado a fin de homogeneizar un conjunto de leyes que, con sus modificaciones, estaban vigentes desde la década de 1880. De todos modos, el punto central era el capítulo del reclutamiento, nudo de toda legislación militar. Así, la adecuación legislativa estaba planeada para, a un mismo tiempo, resolver cuestiones de fondo, corregir falencias y atender los reclamos más urgentes.

En lugar del habitual mensaje de fundamentación, el poder ejecutivo remitió un anexo que daba cuentas de los cambios a introducir. Apenas ingresado el asunto en la cámara baja, el diputado santafesino y coronel Rodolfo Domínguez fundamentó el proyecto y pidió pronto tratamiento a sus compañeros de bancada, al sostener que la ley 4.031 tenía defectos "que han sido demostrados en la práctica". El nuevo ordenamiento intentaba reconstruir la "disciplina en el ejército, que no existe desde hace tiempo. Por eso son los alzamientos en los cuarteles". ${ }^{44}$

La extensión y complejidad del proyecto, así como la urgencia por dar respuestas a los temas más urticantes, llevaron a los legisladores a dejar de lado una buena parte de las reformas propuestas, como el rediseño de la intendencia militar. Por otra parte, un análisis pormenorizado de la ley y sus debates excede largamente los límites de este artículo, de modo que nos concentraremos en aquellos aspectos más relevantes vinculados con nuestro planteo.

43 DSCD, 1905: I, 377-378.

44 DSCD, 1905: I, 377. 
A diferencia de los planes esbozados por Riccheri en 1901, y a pesar de la gran cantidad de problemáticas que abordaba, los objetivos institucionales del proyecto eran muchos más terrenales y se ajustaban mejor a las limitaciones presupuestarias. En palabras del propio ministro de guerra, los efectivos, por escasos que parecieran, se habían calculado "para un número de unidades reglamentarias mucho más modesto". ${ }^{45} \mathrm{La}$ ambición de Godoy no eran los grandes ejércitos europeos, sino el austero modelo militar japonés, que con su pequeño núcleo de soldados en servicio permanente y grandes reservas de milicianos con una buena instrucción, había conseguido una victoria tan espectacular como fulminante en la guerra contra el imperio ruso unos pocos meses antes. ${ }^{46}$

El pensamiento de Godoy fue ratificado sin ambages por el senador Salvador Maciá quien al actuar como miembro informante en la cámara alta dijo: "Nuestro ejército no tiene más misión que la de policía del orden; la policía de frontera, única policía de seguridad que hoy el ejército puede desempeñar, está encomendada á cuerpos de gendarmería, á los cuales no van los conscriptos sino cuando son infractores a la ley" ${ }^{47}$ Para este fin bastaban unos pocos soldados, sin comprometer el presupuesto pues "la base prudente de 4, 5 ó 6,000, que puede adoptar el Poder Ejecutivo, con arreglo á la modificación que la Comisión hace; demuestra que es la única que está dentro de nuestro estado financiero actual' ${ }^{48}$

En tal sentido, el primer dato saliente era la reducción del plazo de la prestación, ya que el gobierno pensaba llamar únicamente a unos 5.000 soldados por un año mientras la mayoría de la clase sería convocada para una instrucción de tres meses, algo con cierto parecido al modelo adoptado en 1895. Si bien el acortamiento del período del servicio no recibió objeciones, esa cantidad tan pequeña de reclutas generó bastante polémica en la discusión en particular. ${ }^{49}$

45 DSCD, 1905: II, 195.

46 Idem, 1905: II, 191.

47 DSCS, 1905: 899.

48 DSCS, 1905: 899.

49 En efecto, mientras ese número de soldados fue sostenido por el ministro, el general Campos y la mayoría de la comisión de guerra pedían 10.000 efectivos de un año y excepción del servicio para el resto de la clase. Una tercera postura era la de Julio Roca (h) y Mariano Demaría, quienes solicitaban 10.000 hombres por un año y el resto de la clase por tres meses. En diputados esta última moción prevaleció, pero fue revertida en la cámara de senadores, donde el artículo se reformó de acuerdo al interés del ejecutivo. Diputados no insistió y finalmente el texto definitivo quedó como en el proyecto. Los debates sobre esta discusión pueden leerse en DSCD, 1905: II, 195-203. 
Una segunda cuestión de trascendencia era el deseo de la ley de fortalecer el voluntariado, sobre todo para atraer cabos y sargentos, una de las metas centrales de la ley 4.031, que en sus tres años de funcionamiento apenas había conseguido un millar de suboficiales contra los 3.500 calculados por Riccheri en 1901. La idea del gobierno era reclutar 5.800 voluntarios, dentro de los cuales se contaban a los suboficiales, los soldados voluntarios, pero también a los médicos, veterinarios, músicos, artesanos, herreros, etc. De resultas entonces, el nuevo ejército proyectado poseería más enganchados que conscriptos de un año. Bien lo enfatizó el senador Maciá al explicar que "por la tendencia de esta ley, el voluntariado es la base de la estabilidad del ejército, alrededor del cual debe desarrollarse la instrucción de los conscriptos; y no hay razón para limitarla". ${ }^{50}$

Como tercera consideración, debe decirse que el proyecto oficial estaba lejos de modificar los criterios sociales para el reclutamiento: no solamente se ampliaban las condiciones para que los estudiantes superiores solamente cumplieran el servicio de tres meses y con ello obtuvieran un despacho de oficial de reserva, sino que quienes acreditaran su condición de tiradores también pasarían por una prestación mínima. Pero, para quitar un aspecto muy odioso de la Ley Riccheri, se eliminaba la permuta. ${ }^{51}$ Igualmente este instituto no había funcionado en la práctica dado que para los grupos sociales acomodados era más sencillo eludir directamente la ley que enredarse en sus laberintos.

El cuarto elemento que deseamos aislar era la abrogación de la antigua ley de ascensos, de 1882, sindicada como una de las herramientas que, por su permeabilidad a la arbitrariedad, más irritaba a la oficialidad joven. En el título donde se estructuraba la carrera profesional, la novedad saliente fue la conformación de un tribunal de calificaciones y una comisión de ascensos, que en el sector bajo de la escala priorizaba la antigüedad por sobre la elección, algo que resguardaba las chances de los oficiales menores carentes de padrinazgo político. En definitiva, para los oficiales de menor rango (como subtenientes y tenientes), se decidió una mayor ponderación a la antigüedad; en los intermedios (capitanes y mayores), a partes iguales; y en los de mayor jerarquía (tenientes coroneles y coroneles), preponderancia de la elección. 
El quinto y último punto para subrayar fue el cumplimiento del reclamado cierre del escalafón y la eliminación de los cuadros supernumerarios en su parte más alta, medida que se componía por la determinación de números máximos de oficiales que podían revestir en cada grado, y un programa de retiros de los excedentes mediante condiciones muy beneficiosas de jubilación, gracias a las cuales muchos jefes y oficiales superiores pudieron retirarse con la pensión del grado mayor al que poseían. Sobre esto fue claro el diputado Domínguez, al sostener que "no es ningún misterio para nadie que la generación actual de nuestra oficialidad, en los grados medios y subalternos, tiene justos motivos para estar desalentada y para perder el estímulo, en presencia de esa montaña que pesa sobre ellos por el exceso de jefes que ha producido el abuso en el otorgamiento de los ascensos". ${ }^{2}$

Finalmente, quedaba todavía pendiente la situación de los oficiales encarcelados y dados de baja tras la asonada de febrero. Al respecto, el 21 de agosto, mientras se discutía la ley, ingresó un proyecto del diputado porteño Manuel de Iriondo que postulaba una amnistía amplia a quienes habían tomado parte en la revolución radical. Aunque el mensaje resultaba algo contradictorio, ya que los diputados hablaban permanentemente de tratar de erradicar la indisciplina y la política dentro del ejército, fue saludado con aplausos de la barra para el orador y sin ninguna observación o crítica de sus colegas. De todas maneras, la renuencia del presidente Quintana y del ministro Godoy a consentir tal cosa dejó la iniciativa en suspenso. Solo al año siguiente, ya con Figueroa Alcorta en la Casa Rosada y Luis María Campos en la cartera de Guerra, no solamente se sancionó una amnistía amplia sino que se aprobó la reincorporación a filas de los sublevados de 1905.

\section{Los desarrollos institucionales posteriores a 1905}

Todo este trabajo encarado de reforma de la ley orgánica del ejército en 1905, tuvo un fuerte impacto en varios aspectos del mundo militar. Pero el hecho es que a su vez fue acompañada por una serie de modificaciones menores en los años siguientes, que terminaron por consolidar la legislación por décadas. Una primera cuestión no menor,

52 DSCD, 1905: II, 181. 
tanto en lo simbólico como en lo material, fue la eliminación del estatuto del "personero", ya por entonces fuertemente criticado e identificado con una sociedad vetusta. Esta figura había sido prorrogada en la "Ley Riccheri” bajo la denominación de "permuta" y permitía la dispensa de la prestación personal a quien pudiera pagar a alguien en su lugar. Junto a esto, y como ya lo hemos visto, se produjo la restitución del "voluntario" junto con el SMO. ${ }^{53}$ Esto no debiera sorprender puesto que en las últimas dos décadas del siglo XIX la opción de un servicio forzado en el ejército, que había sido fuertemente resistida al interior del mundo militar, ${ }^{54}$ fue simplemente dejada de lado en la "Ley Riccheri" aunque subsistió como opción real en una parte de la oficialidad.

El tema es que el debate sobre el voluntariado en realidad estaba conectado con otro problema que se había agravado desde la sanción de la "Ley Riccheri": el de las clases (años más tarde “suboficiales"). ${ }^{55}$ El servicio de dos años establecido desde 1901 para la quinta parte convocada (destinada a formar precisamente suboficiales) no había dado ningún resultado significativo. Incluso la legislación de 1905 debió ser retocada en este punto, cuando se sancionaron al año siguiente algunas modificaciones a la ley. ${ }^{56}$ Otra cuestión que a tenor de los propios juicios militares ganó en operatividad, fue el de la concepción regional de la división territorial pero también su organización interna. Sobre las antiguas cuatro "Comandancias de Frontera" organizadas en las décadas de 1860 y 1870, se proyectó en 1888 y por primera vez una organización territorial dividida en regiones. Aunque no tuvo prácticamente ningún impacto en la ubicación concreta de las fuerzas (pues había sido pensada como un programa de

53 El 21 de diciembre de 1906 se aprobó la ley 5.043, que modificó muy parcialmente la de 1905. En su artículo 44 estipuló que el ejército constaría, de allí en más, con un mínimo de cinco mil voluntarios. La edad de admisión quedó señalada entre 17 y 30 años, ver CLyDM, 1907: 114.

54 Avellaneda, 2017b.

55 Es necesaria una pequeña digresión terminológica. En la ley de 1901 se denominaba "clases" a soldados y cabos, utilizándose el término "suboficial" para los sargentos. Unos pocos años más tarde, el término se estabilizará alrededor de esas últimas dos categorías.

56 En el debate de 1906 para modificar cinco artículos de la ley 4.707, el diputado Mateo Ruiz Díaz, como miembro informante de la Comisión de Guerra, sostenía en contra del servicio militar de tres meses y a favor de una ampliación del número de voluntarios que con respecto a la cuestión de los suboficiales: "basta la fecha no se ha podido obtener de otra fuente que la del voluntariado, pues ni de los conscriptos de dos años que con ese objeto establecía la anterior ley 4031, ni con los conscriptos de un año de la ley actual, se ha conseguido que continuaran en el servicio los que resultaban aptos para clases, pues cuando llega la época del licenciamiento se van todos", DSCD, 1906: 569. 
movilización general en caso de estado de guerra), puede señalarse como el antecedente directo de aquella que, más conocida, comenzó a tomar forma luego de la sanción de la ley de organización del ejército de 1895. El punto que liga ambas legislaciones es la preocupación por conectar con los recursos y futuros combatientes, en un caso para movilizarlos, en el otro para instruirlos.

De las seis regiones diagramadas en 1895 y elevadas a siete al poco tiempo, la "Ley Riccheri" dispuso diez, que nuevamente y en pocos meses se redujeron a siete (Capital Federal, Neuquén, Uruguay, Litoral, Cuyo, Centro y Norte) ${ }^{57}$ Su organización general resultó muy cuestionada en los debates de 1905. Un problema casi inédito, y creado por Riccheri, fue la creación de regiones militares que dividían provincias (algo que siquiera había sucedido en el primitivo proyecto de 1888). Debido a ello, el general Godoy en su mensaje anexo al proyecto de ley orgánica del ejército de 1905 trataba de justificar su rechazo a la organización territorial existente y manifestó que cualquier división regional podía agrupar provincias, pero no seccionarlas: "La más elemental prudencia nos aconseja utilizar estos organismos vivientes, en vez de partirlos para reunir después sus fragmentos dispersos" ${ }^{58}$

No solamente se redujo el número de regiones y se dotó a la organización territorial de un mayor ajuste en función a la población masculina objeto de instrucción militar de cada espacio de cobertura, sino que el interior de cada región resultó materia de divisiones y subdividisiones territoriales que provocaron una mayor consistencia en los circuitos de traslado de información relativa a los enrolamientos y sorteos. ${ }^{59}$ Junto con la organización de las nuevas cinco regiones militares (Capital Federal, Sud, Litoral, Centro y Cuyo, y Norte) se diseñó un esquema de centros y sub-centros de sistematización de información y cálculos, comenzando por los comandos de distrito (denominados "Distritos de reclutamiento y movilización"), Comandos de sub-zona y de zona, pasando por los Comandos de Región, hasta llegar al Estado Mayor. ${ }^{60}$

57 Ver CLyDM, 1902: 272-273.

58 DSCD, 1905: I, 405.

59 Para la nueva división territorial de 1905, ver CLyDM, de 1905, "Aprobando el proyecto de Subdivisión Territorial", pp. 1-8. Los números del enrolamiento ya habían mejorado sensiblemente en los últimos años del siglo anterior, llegando a tener un registro de varones en edad de instrucción o servicio militar, similar al del censo de 1895, Avellaneda, 2019.

60 Esto fue implementado de modo progresivo, comenzando por la primera región militar. Recién a partir de 1907-1908 el esquema de subdivisión regional comenzó a aplicarse al resto de las regiones. 
Mientras de forma ascendente esto posibilitaba la producción de datos agregados a varios niveles que iban componiéndose a medida que las oficinas recibían información desde distintos nodos, en forma descendente se vehiculizaban autorizaciones e indicaciones diferenciadas de acuerdo no solamente a cada región o zona sino también a cada distrito. ${ }^{61}$

Muy posiblemente hayan sido estas redes de una mayor densidad comparativa las que posibilitaron una percepción de adelantos en estos temas en el segundo quinquenio de la primera década y en los años siguientes. Se comenzó a apreciar que las redes técnicas y materiales que posibilitaban los enrolamientos y los sorteos provocaban finalmente un mayor agarre territorial y una mayor sinergia con otros organismos estatales, tanto nacionales como provinciales. Producto de esto, el ejército comenzó a incrementar los porcentajes de personas enroladas y, sobre una proporción de estas aunque no en el mismo ritmo, su envío a los cuarteles (que para los casos de transporte por tren y a pesar de los reclamos, seguiría siendo efectivizado en vagones de carga). ${ }^{62}$ En 1909 se intentaron profundizar los detalles en estos aspectos, pero las controversias sobre la jurisdicción militar o civil de los conscriptos fue uno de los asuntos que bloqueó la iniciativa. Para 1911, estaban diseminadas por todo el territorio 269 oficinas enroladoras y se proyectaban más de cuatrocientas. ${ }^{63}$

Finalmente, un espacio institucional que emerge de modo estable en estos años es el de la formación de los futuros suboficiales. Este espacio de formación particular, contaba hasta allí con una vida más bien corta, pues había surgido recién a finales del siglo XIX con la "Escuela de Cabos y Sargentos" que tuvo una vida oscilante y marginal hasta 1890, cuando resultó suprimida a la vez que se creó la "Escuela Normal de Clases del Ejército". No sin antes intentar avanzar con una "Escuela TeóricoPráctica para Clases" (1899), el Ejército instituyó, por medio de la "Ley Riccheri”, la

61 Un ejemplo de esto es el periodo de licenciamiento de los conscriptos, que recién a fines de 1907 se organizó por primera vez de modo integral y diferenciado de acuerdo a las regiones militares. Así, los conscriptos de las regiones militares segunda y cuarta pasaron a ser licenciados el 31 de diciembre de cada año, mientras que aquellos de la primera, tercera y quinta región finalizarían su periodo el último día de febrero. Algo similar ocurrió para los periodos de reconocimiento médico en los casos de incorporación. En los años siguientes cambiaron las fechas, pero ya no este principio de organización temporal general aunque diferenciado de acuerdo a las regiones.

62 Ver CLyDM, 1907: 171.

63 CLyDM, 1911: 790-800 
"Escuela de Aplicación de Clases" que llegó a durar cuatro años, hasta ser el intento clausurado, una vez más, debido a la ausencia de aspirantes y a la poca efectividad de los medios para conseguirlos como ya hemos narrado. La "Escuela de Clases" creada en 1908 - que cambió su denominación en 1916 por la de "Escuela de Suboficiales" no estuvo exenta de contratiempos en cuanto al reclutamiento de personal pero sus vicisitudes comenzaron a calmarse a finales de la segunda e inicios de la tercera décadas, cuando los cuadros vieron garantizados un número anual estable de incorporaciones. ${ }^{64}$ La dramática escasez de suboficiales fue una de las cuestiones centrales que plantearon los proyectos presentados en 1909 y 1912 para reformar la ley 4.707. ${ }^{65}$ Si bien ambos coincidían en la necesidad de hacer ajustes en los mecanismos del reclutamiento, estos intentos preveían contratos más extensos y mejor remunerados y premios en dinero por permanencia en filas nada despreciables, además del beneficio de liberar del servicio a los hermanos menores del enganchado. En 1912, además, se insistía con recrear un servicio de dos años como fuente para obtener el personal subalterno. De todas formas, el proyecto de 1909 naufragó al debatirse en diputados y el de 1912 ni siquiera tuvo tratamiento parlamentario.

\section{El mundo militar camino del centenario y más allá}

El 12 de marzo de 1906 se realizaron elecciones legislativas en varias provincias y en la Capital Federal. Los métodos de esos comicios fueron los tradicionales hasta entonces (manipulación de las mesas de sufragios, fraude, compra de votos, etc.), sus resultados en cambio mostraron la dispersión del poder de un grupo gobernante cada

64 De acuerdo a los diagnósticos emitidos en esos años, difícilmente se le podría asignar a este espacio un peso ascendente en la formación técnica y moral de los suboficiales. El número de egresados de las sucesivas promociones desde 1912 parece haber ido en constante descenso, al menos hasta finales de esa década (Revista del Suboficial, abril de 1920, p. 296). A ello había que agregar las preocupaciones por los niveles de deserción de los que egresaban de la Escuela, debido en lo fundamental a lo magro del salario. Los números serían otros en los primeros años de la década de 1920.

65 El 21 de junio de 1909 el poder ejecutivo remitió a la cámara de diputados un extenso proyecto de ley orgánica para el ejército, que incluía en sus 332 artículos una amplia revisión de la ley 4.707 y presentaba por primera vez un capítulo dedicado a las requisiciones. Fue aprobado en general y tratado en particular durante julio ese año, pero finalmente se devolvió en revisión a la comisión de guerra, donde quedó olvidado. Su presentación y tratamiento en DSCD, 1909: I, 86-133 y 303-464. El proyecto de 1912 ingresó en sesiones de prórroga, en noviembre de ese año, sin conseguir despacho, véase $D S C D$, 1912: III, 17-44. 
vez más complicado para funcionar como bloque compacto. Pero el dato más saliente de la jornada fue la noticia del fallecimiento del presidente Quintana, complicado por sus dolencias desde inicios del verano. La sucesión constitucional dejó como jefe de la Casa Rosada a José Figueroa Alcorta, el entonces vicepresidente. Exgobernador y exsenador por Córdoba, no era la figura política más importante del momento. Puesto en la fórmula del ejecutivo después de realizadas las elecciones y a efectos de compensar al porteño Quintana, tenía escaso anclaje territorial y poco o nada se sabía de sus intenciones, aunque se conocía su enemistad con Roca. ${ }^{66}$

Justamente esa debilidad de origen lo indujo a recostarse en el ejército para poder consolidar su poder. Tras unos primeros tiempos bastante vacilantes, entre 1907 y 1910 prácticamente liquidó lo remanentes del roquismo, puso de rodillas a un congreso que lo hostigó con denuedo, logró deshacerse de importantes caudillos provinciales y consiguió imponer de manera canónica al sucesor elegido: Roque Sáenz Peña. Sin un poder propio, como ninguno de sus antecesores se valió del ejército como un partido presidencial. En gran medida, Figueroa Alcorta recogió los frutos de la nacionalización de los servicios militares y - gracias a algunos de los cambios analizados anteriormente y al alivio del malhumor de los oficiales (lo que detuvo los alzamientos cuarteleros) le dio a las fuerzas de tierra una presencia territorial que las convirtieron en garantes de la voluntad del jefe de gobierno. En línea con las ideas sostenidas por el senador Maciá, esa "policía del orden” sirvió como columna central del control político.

Sin embargo, no fueron demasiados los progresos hechos al interior del ejército en aquellos puntos señalados como grandes defectos de la organización institucional. Las reservas siguieron sin ser convocadas a ejercicios de repetición, a pesar de que el texto de la ley 4.707 enfatizaba en ellas y en sus debates fue uno de los temas señalados como déficit significativo de la gestión de Riccheri. Recién en 1908 se comenzó la tarea de confeccionar un registro de reservistas, un listado fundamental si se quería convocar a esas personas, ${ }^{67}$ y solamente en 1910 fueron llamadas por un mes (del $1^{\circ}$ al 31 de

66 Melo, 1970: 310-311

67 CLyDM, 1908: 437. 
mayo), con el único efecto de practicar para el gigantesco desfile militar a brindarse en ocasión del Centenario. 68

A diferencia de las grandes maquinarias bélicas de su tiempo, tampoco el ejército nacional se empeñó en hacer de las maniobras una cuestión de importancia. Fuera de los antecedentes de 1892 y 1896 (este último con la "primera conscripción"), hasta 1909 en Argentina “maniobras" fue el equivalente de desfiles; esta era otra de las quejas más duras manifestadas contra Riccheri durante su paso ministerial. La inutilidad de los campos militares destinados a ese fin era tan manifiesta que en 1906 se decidió licitar el arriendo con destino a la producción agropecuaria de la mayoría de ellos, o de fracciones no usadas para fines militares aun en aquellos terrenos considerados de importancia táctica, de modo de permitir el ingreso de dinero a las arcas de la tesorería. ${ }^{69}$

La preocupación por la falta de ejercitación de los cuerpos fue objeto de las quejas de Augusto Maligné, quien se lamentaba de que ni siquiera se intentaban hacer maniobras de medio rango concentrando alguna brigada de 3.000 hombres durante un mes y denunciaba la "peligrosa mistificación" de pretender enseñar la guerra "sentados en un banco de escuela, sin contacto con las unidades tácticas". ${ }^{70}$

En idéntico orden se expresó poco después en un largo memorando el teniente coronel alemán Perrinet von Thauveney, quien afirmó: "Hasta ahora ningún comandante de batallón, ningún jefe de compañia ba conducido, en tiro de combate, con todos sus vebiculos, ni mucho menos un grupo, regimiento o brigada en pie de guerra". ${ }^{71}$ Recién en la primavera de 1909 se llevaron a cabo maniobras de mediana importancia en Córdoba. No fueron motivadas tanto por ensayar juegos de guerra en vista de un conflicto con un ejército enemigo, sino mucho más como respaldo al comisionado nacional enviado por el presidente para intervenir esa provincia pocas semanas antes del inicio de las maniobras ${ }^{72}$.

68 Memoria del Ministro de Guerra, en adelante MMG, 1910: 9.

69 CLyDM, 1906: 71-72.

70 "El servicio en el Estado Mayor y la Escuela Superior de Guerra" (en Revista Militar, 1906, pp.107111).

71 Ver Palombo, 2001: 665. Esta notable pieza de un observador extranjero calificado quedó olvidada hasta su traducción del alemán en 1999 por Guillermo Palombo, que la presentó como parte de su ponencia en las II Jornadas de Historia Militar Argentina.

72 Quinterno, 2014: 446-448. 
Más allá de su verdadero objetivo, Figueroa Alcorta pudo mostrarlas con orgullo ante el congreso, en mayo de 1910, cuando exclamó: "puede decirse que es la primera vez que se realizan maniobras de esta clase en el país, con participación de un numero considerable de tropas de todas las armas". ${ }^{73}$ A pesar de esto, las limitaciones presupuestarias llevaron a suspenderlas desde 1910, ${ }^{74}$ y volvieron a convertirse en una obsesión para Maligné quien seguía insistiendo en su reclamo: "Si alguna vez se imprime otra dirección a nuestro ejército, el primer programa deberá ser 'maniobras primero, maniobra después y maniobras todavía". ${ }^{75}$ Los ejercicios se retomaron en el otoño de 1914 en Entre Ríos, pero los problemas observados en las prácticas, los desajustes operativos, la temporada del año escogida y otras cuestiones funcionales que dejaron un saldo lamentable, terminaron en la interpelación del entonces ministro de guerra Gregorio Vélez. ${ }^{76}$

Ya hemos hablado del problema estructural en torno al reclutamiento de suboficiales, un personal sin el que era inviable pensar en una fuerza de más de 12.000 soldados. El tema también llamó la atención del comandante germano ya citado, quien que subrayó lo siguiente: "teóricamente, debería ser fácil obtener buenas clases de un material de soldados tan buenos. Mas en la práctica, faltan de un modo verdaderamente alarmante”. Pocos párrafos más adelante en su relato dejó caer la conclusión obvia: “Ante todo, debe pagárseles mejor. En un pais en que se paga a precios elevados el trabajo más sencillo y de ninguna responsabilidad, es necesario remunerar mejor el trabajo dificil y de gran responsabilidad del suboficial'. ${ }^{77}$

El propio ministro Racedo lo manifestó en su memoria anual de 1910 al escribir sobre sobre la imposibilidad de atraer aspirantes hacia la escuela de clases, y como paliativo alentó la instalación de oficinas de enganche a lo largo de todo el país, cuyo fin era incorporar individuos "relativamente seleccionados". 78

Pero esas facilidades de la economía nacional también hicieron cada vez más complicado nutrir a los cuerpos con oficiales sacados del Colegio Militar, a punto tal que en 1908 las fuentes oficiales consignaban una "penuria de oficiales" en los grados

73 Mabragaña: VI, 476.

74 Jáuregui, 1915: 97.

75 Maligné, 1913: 29.

76 DSCD, 1914: I, 541-544 y 632-670. En esas maniobras fallecieron siete conscriptos y un capitán, este último embestido por una locomotora.

77 Palombo, 2001: 657.

78 MMG de 1909-1910, p. 33. La cursiva es nuestra. 
inferiores. ${ }^{79}$ Esa insuficiencia obligó poco más tarde a admitir oficiales de la reserva y promover subtenientes con tres meses de instrucción para llenar las vacantes en los niveles más bajos del escalafón. ${ }^{80}$

Algo que no desapareció en absoluto entre las preocupaciones de los oficiales fue la política, en especial entendida como derechos cívicos y participación partidaria de los militares. El asunto fue objeto de reflexiones varias durante la discusión legislativa de 1905, pero también circuló en los años siguientes en forma de artículos en la Revista Militar y no faltaron los estudiantes de abogacía que eligieron ese objeto de estudio en sus tesis, tal como lo hizo Guillermo Teobaldi en 1908 (y luego reproducida por partes en el mensuario uniformado). ${ }^{81}$ Para nuestro oficial alemán ya presentado, el nivel de las discusiones políticas dentro de los cuarteles era intolerable y calificó como "verdaderamente deplorable la influencia que esta ejerce en todo el ambiente". En su opinión, este "punto débil de la oficialidad" relajaba la disciplina y el gobierno era el principal responsable de la situación mientras se "alimente en los oficiales el concepto de que una revolución con éxito no puede traer sino ventajas, y una revolución sin éxito ninguna desventaja". ${ }^{2}$

También a fines de 1909 coincidía con esta visión crítica el general retirado Ignacio Fotheringham, quien en su autobiografía señaló: "De las disposiciones tomadas, emana la amarga reflexión que más vale ser 'revolucionario' que no. A los primeros hay que conquistarlos; a los otros: "que los olviden, están seguros". ${ }^{83}$ Como puede apreciarse, a las puertas del Centenario los militares argentinos mantenían lozanas las tradiciones de la injerencia en política y el recurso a la revolución, a punto tal que otro visitante ilustre - en este caso llegado para las celebraciones de las fiestas mayas de 1910 - reflejó su sorpresa por los rumores de un clima de malestar y revuelta en algunas provincias a pesar de la aparente tranquilidad reinante: "en Rosario como en Tucumán más tarde, recogi extraños propósitos sobre las probabilidades de una revolución. 'Tal jefe militar estaba descontento y, si no se le daba satisfacción, podría temerse un movimiento. Despachos del gobierno prescribian vigilar sobre los depósitos de armas, etcétera" ${ }^{84}$

79 MMG de 1907-1908, p. 70.

80 CLyDM, 1909: 489-490.

81 Teobaldi, Guillermo, Condición politica del militar, Imprenta de Adolfo Grau, Buenos Aires, 1908.

82 Palombo, 2001: 654.

83 Fotheringham, 1971: II, 113.

84 Clemençeau, 1986: 156. 
Incluso hacia 1913, ya sancionadas las leyes electorales y en un clima de relativa paz política y social, el entonces general de división Pablo Riccheri - en su condición de presidente del Círculo Militar - reclamó atención sobre la politización creciente y poco más tarde, en 1915, hasta se permitió incluir la misma admonición en la ceremonia de despacho de los subtenientes egresados del Colegio Militar de la Nación. ${ }^{85}$

Además, la mayoría de los publicistas no tenían dudas acerca de la permanencia de la influencia radical entre la oficialidad media y baja. Según el dirigente Ricardo Caballero, ese grupo y la juventud eran la esperanza del partido, ${ }^{86}$ y tal opinión la compartía el catedrático Pedro Arata, quien en febrero de 1908 le advirtió a su amigo Roque Sáenz Peña que una coalición mitrista y roquista en ese momento traería otra revolución de la UCR: "El ejército es hoy radical y el gobierno tendrá que apoyarse en estas fuerzas hoy sin cabeza, o gobernadas por gente de poco cacumen". Arata coincidía con Caballero en las simpatías uniformadas hacia Yrigoyen, pero creía que Sáenz Peña debía utilizar a los radicales para sus propios fines políticos y así se lo recomendaba. ${ }^{87}$

\section{Conclusión}

En dos aspectos bien puntuales, la "Ley Riccheri" ha dejado sin dudas una marca singular, tal como lo hemos tratado de señalar en trabajos anteriores. En primer lugar, en las controversias y disputas entre poderes provinciales y el estado nacional por la capacidad de disponer de grupos armados, de pertrecharlos, organizarlos e instalar sus propias líneas de comando. En ese sentido, la "Ley Riccheri" inclina fuertemente la balanza hacia la nacionalización de los recursos militares, y su centralización en manos del Ministerio de Guerra y el ejecutivo presidencial.

En segundo lugar, en acercar argumentos ajenos al mundo militar para convalidar una de las opciones de dotación de recursos del ejército. El primer intento de dotación exclusiva por contingentes de 1888, pero incluso el programa de instrucción militar de 1895, no habían sido apoyados por los cuadros militares con argumentos relativos a

85 Noro \& Brown, 1999: 180

86 Rouquié, 1986: 100.

87 Pedro Arata a Roque Sáenz Peña, febrero 12 de 1908. Academia Nacional de la Historia, Fondo Roque Sáenz Peña, caja 20, folio 50. 
los beneficios etno-cívicos de la población masculina joven. En ambos casos los soportes habían llegado desde unos marcos de justificación exclusivamente militares (dotar de recursos en el marco de la empresa de colonización de ese momento, y disponer a los jóvenes a una práctica individual y colectiva de combate, a cielo abierto, en el segundo). En ese sentido, la paradoja es que la "Ley Riccheri" fue, comparativamente, el más “civil” de los proyectos de organización armada esgrimidos hasta entonces. Es justo destacar además que algunos elementos incluidos en ella (como la incorporación de "reservas", entre el ejército de línea y las Guardias Nacionales) son prácticamente una factura original, sin mencionar el hecho de que, a diferencia del programa discutido e implementado desde 1895, en esta se encuentra una filiación mucho más directa con modos de organización militar extranjeros (particularmente la ley francesa de 1872).

Sin embargo, nada de esto nos dice algo relevante en el proceso efectivo de "profesionalización” de combatientes y "modernización” del ejército, aspectos en los que la ley de 1901 ha sido nombrada con asiduidad, y tema sobre el cual hemos dispuesto sus vicisitudes en este artículo. En estas líneas hemos tratado de reponer el sentido de dicha legislación en un marco de larga duración (1880-1910 aproximadamente), a fin de dar cuenta de su lugar en los vaivenes y las preocupaciones en el mundo militar de esos años. Esto nos ha permitido, creemos, justificar la afirmación de que poco o nada novedoso encontramos respecto a lo que allí se legisla en cuanto a dotación de personal e instrucción militar, pues estos asuntos venían siendo terrenos de polémicas y debates por largos años. Incluso en el hecho macizo de llevar efectivamente a los jóvenes a los cuarteles, la ley de 1901 no resultó del todo original ya que, y debido a un retoque menor a la ley de 1895, estos eran el lugar de destino de aquellos desde 1898.

También hemos buscado incluir el contexto político de los años inmediatamente posteriores a la sanción de la ley con el objetivo de visibilizar la relación que los propios actores, tanto de los elencos políticos como del mundo militar, señalaban entre el malestar en el ejército y la situación en la que se encontraba, producto de su propio arrastre histórico pero que, se admitía entonces, se había profundizado luego de 1901. Por último, hemos presentado algunas apreciaciones generales para la época del Centenario, así como señalamos ciertos retoques posteriores a la legislación de 1905. 
Esto, a raíz de dos objetivos ulteriores. Por un lado, marcar algunos aspectos de continuidad entre aquél ejército de fines del siglo XIX y el de 1910. Pero por otro, y en paralelo, indicar algunos lugares en los que la percepción de su espacio organizacional por los propios cuadros comenzaba a cambiar con fuerza (la cuestión de los ascensos y el cierre del escalafón, la redes para el enrolamiento, la operacionalización interior de las regiones militares, entre otros). Y todo esto recién para los días del Centenario y posteriores.

El objetivo principal de este trabajo fue el de poner a consideración de colegas y de quienes concite interés, algunas sospechas sobre la operación de centralización de la "Ley Riccheri" efectuada por los estudios preocupados por la profesionalización y modernización militar o por aquellos que, dándolas por hecho, se dedicaron a estudiar sus "efectos". Creemos que este es un hecho de la historiografía, más que de la historia. Operar una descentralización, no significa solamente asumir que no ha sido vista como un elemento de singular relevancia para los contemporáneos en su relación con las temáticas de la modernización y profesionalización del ejército y que, debido a esto, para los propios actores y en los años posteriores a su implementación, lejos estuvo de haber sido un parteaguas en la propia historia militar. Significa además poner en discusión algunas prácticas con las que nos hemos acercado a los asuntos de la milicia y de la organización armada de esos años. Por caso, la fórmula "servicio militar obligatorio", ¿es realmente diferente de "contingente", "leva" u otros términos similares que daban sentido a no pocas peripecias de la vida militar en la segunda mitad del siglo XIX? E incluso la misma frase "servicio militar", ¿`se la comprendió siempre de un mismo modo? Además, y para no producir una sobrevaloración de la norma, ¿en qué momento los cómputos arrojados por los cálculos de los propios cuadros y, a partir de ellos, sus diagnósticos, comenzaron a dar cuenta de un plano de efectividad de las redes socio-técnicas de agarre territorial y de sinergia interna, para las temáticas de la conscripción, dotación de suboficiales, sanidad militar, ocupación del territorio, entre muchas otras? Dos procedimientos de descentralización entonces. Por un lado, el señalamiento de formas regulares de reflexión en la manera de concebir una fuerza armada; por otro, la identificación de la percepción de los propios actores militares (y otros no militares) de que esas nuevas concepciones tenían fluidez y agarre material, 
junto a la descripción meticulosa de los nuevos y sucesivos ensambles edilicios, logísticos, técnicos, entre otros.

Descentralizar también significa ampliar el rango posible de dimensiones, objetos, actores y procesos, para tomar en cuenta la dirección de los cambios de la organización armada, su tenor así como sus posibles impactos. El periodo de la Gran Guerra y de la Revolución Rusa no ha sido atendido hasta aquí como un aspecto a considerar en las metamorfosis del ejército. Tampoco el periodo en el que el Gral. Justo estuvo a cargo del Ministerio de Guerra, cuando un renovado ambiente de ilustración militar invadió las publicaciones castrenses y novedosos proyectos relativos a doctrina, movilización y organización, armas, pero también camaradería y función social, fueron pensados, e incluso algunos, implementados. Todos ellos, o la mayoría, aguardan y a la vez merecen ser estudiados. 


\section{FUENTES}

Cámara de Diputados de la Nación, Diario de Sesiones de la Cámara de Diputados, años consultados: 1900, 1902, 1905, 1906, 1909, 1912, 1914. Imprenta del Congreso de la Nación.

Cámara de Senadores de la Nación, Diario de Sesiones de la Cámara de Senadores, años consultados: 1904, 1905. Imprenta del Congreso de la Nación.

Círculo Militar, Revista Militar, Imprenta del Arsenal de Guerra, Buenos Aires. Periodo consultado, 1884-1910

Domínguez, E. 1925, Colección de leyes y decretos militares, Compañía Sudamericana de billetes y Banco, Buenos Aires. Periodo consultado: 1870-1924.

Fanelli, V. 1905, Justificatio. Causas y origen de los sucesos del 4 de febrero de 1905, S/e, Buenos Aires.

Fotheringham, I. 1971, La vida de un soldado o reminiscencias de la frontera, Círculo Militar, Buenos Aires.

Gez, J. W. 1905, Vindicación constitucional. La Revolución de San Luis, Imprenta, Litografía y Encuadernación de la fábrica «La sin Bombo», Buenos Aires.

Gómez, J. 1905, Mi defensa (Escrito presentado al Juzgado Federal de Mendoza, explicando las causas que me decidieron a tomar parte en la Revolución del cuatro de febrero), Imprenta y Librería de L. de la Cruz, Valparaíso.

Jáuregui, E. 1915, Asegurar la paz, Jacobo Peuser, Buenos Aires.

Mabragaña, H. 1910, Los mensajes. Historia del desenvolvimiento de la Nación Argentina redactado cronológicamente por sus gobernantes. 1810-1910, Tomos V y VI, Imprenta de la Compañía General de Fósforos, Buenos Aires.

Maligne, A. (Tte. Cnl.). 1904, El ejército argentino por dentro. Estudio para contribuir al restablecimiento de nuestras instituciones militares arruinadas, Imprenta La Harlem, Buenos Aires.

Maligne, A. 1910, Historia militar de la República Argentina, Diario «La Nación», Buenos Aires.

Maligne, A. 1913, Historia y crítica militares, Librería Moderna de Bernardo Lourbière, Buenos Aires.

Matienzo, J. N. 1910, El Gobierno Representativo Federal de la República Argentina. Coni Hermanos, Buenos Aires.

Ministerio de Guerra y Marina (posteriormente, Ministerio de Guerra),
Memorias del Ministerio, Imprenta del Arsenal de Guerra, Buenos Aires. Años consultados: 1887, 1888, 1889, 1894, 1896, 1908, 1909, 1910.

Ministerio de Guerra. 1905a, Proceso de la Rebelión del 4 de febrero de 1905 en la Capital Federal. Fallos y antecedentes del Consejo de Guerra Especial. Talleres Gráficos del Arsenal Principal de Guerra, Buenos Aires.

Ministerio de Guerra. 1905b, Proceso de la Rebelión del 4 de febrero de 1905 en Córdoba. Fallos del Consejo de Guerra Especial. Imprenta Argentina, Córdoba.

Ministerio de Guerra. 1912, Cuerpo de leyes orgánicas del Ejército de la Nación. Proyecto presentado por el Poder Ejecutivo al $\mathrm{H}$. Congreso de la Nación el 7 de octubre de 1912. Talleres Gráficos del Arsenal Principal de Guerra, Buenos Aires.

Navarro, D. 1906, Tragedia de Pirovano. Homicidios y robos ocurridos el 6 de febrero de 1905, Taller Gráfico A. Gasperini \& Cía. La Plata.

\section{BIBLIOGRAFÍA}

Avellaneda, A. 2016, "Del cálculo de las fronteras a la elaboración de un interior: diagnósticos y proyectos sobre el espacio en los cuadros militares argentinos a fines del siglo XIX" en Revista Universitaria de Historia Militar, Vol. 5, Núm. 10, pp. 241 a 216.

Avellaneda, A. 2017, "El ciudadano de las barracas. Genealogía del servicio militar como problema y preocupación en los cuadros militares argentinos en la esquina de los siglos XIX-XX" en Coordenadas. Revista de Historia Local y Regional, año 4, Núm. 3, pp. 57 a 86.

Avellaneda, A. 2017b, "Racionalidad militar e ingreso voluntario al Ejército a fines del siglo XIX. Ideas, sueños e hipótesis de una batalla perdida" en Estudios Sociales del Estado, Vol. 3, Núm. 6, pp. 124 a 156.

Avellaneda, A. 2019, "Mundo Militar y gobierno a distancia. Redes para el enrolamiento y sorteo militar de los jóvenes entre 1880 y 1910" en Pasado Abierto, Núm. 10, pp. 204 a 241.

Barba, F. 2000, "Marcelino Ugarte, la Provincia y la Nación, estilos de gobierno" en Anuario del Instituto de Historia Argentina, Núm. 1, pp. 25 a 44.

Barcia, J. 1981, "Las revoluciones radicales" en Todo es Historia, Núm. 170, pp. 75 a 84. 


\section{A. Avellaneda \& H. Quinterno 26/27: pp.67-102 \\ Cuadernos de Historia. Serie economía y sociedad}

Beamonde, G. 1985, “A ochenta años de la revolución radical de 1905" en Todo es Historia, Núm. 214, pp. 38 a 46.

Botana, N. 1986, El orden conservador, Hyspamérica, Buenos Aires.

Botana, N. \& Gallo, E. 2007, De la República posible a la República verdadera (1880-1910). Emecé, Buenos Aires.

Caballero, R. 1949, Yrigoyen. La conspiración civil y militar del 4 de febrero de 1905, Raigal, Buenos Aires.

Clemençeau, G. 1986, Notas de viaje por América del Sur. Hyspamérica, Buenos Aires.

Etchepareborda, R. 1968, Tres revoluciones, 18901893-1905, Pleamar, Buenos Aires.

Etchepareborda, R. 1980, "Las presidencias de Uriburu y Roca" en Gallo, E. \& Ferrari, G. La Argentina, del ochenta al Centenario, Sudamericana, Buenos Aires.

Etchepareborda, R. 1984, Historiografia Militar Argentina, Círculo Militar, Buenos Aires.

Fraga, R. 1997, La amistad Roca - Riccheri a través de su correspondencia, Círculo Militar, Buenos Aires.

Fraga, R. 2005, "Dos visiones al momento del centenario, en 1910" en Segundo Congreso Internacional de Historia Militar Argentina, Instituto de Historia Militar Argentina, Buenos Aires, pp. 73 a 98.

Gallo, E. 2007, Colonos en armas. Las revoluciones radicales en la provincia de Santa Fe, Buenos Aires, Siglo veintiuno editores.

García Molina, F. 2001, "La modernización del Ejército y la influencia militar germana (18981904)" en II Congreso Nacional de Historia Militar, Volumen II, Instituto de Historia Militar Argentina, Buenos Aires.

Güembe, M. L. 2015, "De la ciudadanía en armas al servicio militar obligatorio" en Lorez, F. (comp.) Guerras de la Historia Argentina, Ariel, Ciudad Autónoma de Buenos Aires, pp. 249 a 268.

Guzmán, M. F. 1986, "El juicio a los militares revolucionarios de 1905" en Todo es Historia, Núm. 228, pp. 30 a 40.

Melo, C. R. 1970, Los partidos politicos argentinos. Universidad Nacional de Córdoba, Córdoba.

Noro, L. \& Browm, F. 1999, Riccheri: forjador del Ejército Argentino del siglo XX, Editorial María Ghirlanda, Buenos Aires.

Palombo, G. 2001, "La influencia militar alemana en el proceso de modernización del Ejército Argentino durante la primera década del siglo XX" en II Congreso Nacional de Historia Militar, Volumen II, Instituto de Historia Militar Argentina, Buenos Aires.

Peck, D. 1980, "Las presidencias de Manuel Quintana y José Figueroa Alcorta. 1904-1910" en Gallo, E. \& Ferrari, G. La Argentina, del ochenta al Centenario, Sudamericana, Buenos Aires.

Quinterno, H. 2014, Fuego Amigo. El ejército y el poder presidencial en Argentina (1880-1912), Teseo/UAI, Buenos Aires.

Reynolds, F.1969, La revolución del 6 de setiembre de 1930: acción militar, Ismael Colombo, Buenos Aires.

Rock, D. 2006, La construcción del Estado y los movimientos politicos en la Argentina, 1860-1916, Prometeo Libros, Buenos Aires.

Rodríguez, A. 1964, Reseña histórica del Ejército Argentino (1862-1930), Dirección de Estudios Históricos de la Secretaría de Guerra, Buenos Aires.

Rouquié, A. 1986, Poder militar y sociedad politica en la Argentina. Tomo I, Hyspamérica, Buenos Aires.

Silliti, N. 2018, "El Servicio Militar Obligatorio y la 'cuestión social': apuntes para la construcción de un problema historiográfico" en Pasado Abierto, Núm. 7, pp. 265 a 275.

Sommariva, L. 1931, Historia de las intervenciones federales en las provincias, volumen 2, El Ateneo, Buenos Aires.

Yrigoyen, H. 1951, Pueblo y Gobierno, Tomo I, Volumen I, Raigal, Buenos Aires. 